\title{
Análise da representação e recuperação de partituras em catálogos especializados
}

\author{
Analysis of representation and recovery of scores in specialized catalogs
}

\begin{abstract}
Jessica Beatriz Tolare
Mestranda em Ciência da Informação do Programa de Pós-Graduação em Ciência da Informação da Faculdade de Filosofia e Ciências da Universidade Estadual Paulista Júlio de Mesquita Filho - UNESP, campus de Marília,

Brasil.

E-mail: jtolare@gmail.com

ORCID: https://orcid.org/0000-0002-8637-7989

Mariângela Spotti Lopes Fujita Doutora em Ciências da Comunicação pela Universidade de São Paulo - USP, Brasil. Docente Permanente do Programa de Pós-Graduação em Ciência da Informação da Faculdade de Filosofia e Ciências da Universidade Estadual Paulista Júlio de Mesquita Filho - UNESP, campus de Marília, Brasil.

E-mail: mariangela.fujita@unesp.br

ORCID: https://orcid.org/0000-0002-8239-7114
\end{abstract}

\section{Resumo}

A partitura musical é utilizada para representar a música através da escrita. Por ser um tipo de material específico, exige um cuidado especial no tratamento, dentro das bibliotecas com acervos especializados; quando não ocorre esse processo, a precariedade do acervo ou problemas para o usuário recuperá-las causam a perda da partitura. Dessa forma, observou-se a necessidade de verificar e analisar como é realizado o processo de representação em bibliotecas com acervo especializado em partituras. Para isso, foram selecionadas a Biblioteca do Conservatório de Tatuí, a Biblioteca do Instituto de Artes (IA) da UNICAMP, a Biblioteca de Arte da UNESP e o Catálogo de Partituras da USP. Como procedimentos metodológicos, foram adotadas a pesquisa exploratória e analítica, simulações de buscas e recuperações de partituras nesses catálogos. Na verdade, as bibliotecas possuem seu próprio sistema de organização e indexação, sendo que alguns catálogos não apresentam os termos que representam a partitura e não disponibilizam os detalhes do registro, impossibilitando sua visualização. Por isso, pode-se concluir que a partitura requer atenção no seu tratamento como documento e que há necessidade de promover melhorias nos catálogos e no processo de indexação, que visem a padronizar sua representação e recuperação.

Palavras-chave: Representação e recuperação da informação. Informação musical. Partitura musical. Indexação de partitura. Catálogos de bibliotecas.

\begin{abstract}
The musical score is used to represent music through writing. As it is a specific type of material, it requires care in the treatment within libraries with specialized collections; when this process does not occur, precariousness of the collection or problems for the user to recover them cause the loss of the score. Thus, there was a need to verify and analyze how the process of representation in libraries with collections specialized in sheet music is carried out. For this, the Library of the Conservatory of Tatuí, the Library of the Arts Institute (IA), UNICAMP, the Library of Art, UNESP, and the Catalog of Sheet Music at USP were selected. As methodological procedures, exploratory and analytical research, simulations of searches and recoveries of scores in these catalogs were used. Indeed, libraries have their own organization and indexing system, and some catalogs do not have the terms that represent the score and do not provide details of the record, making it impossible to view. Therefore, it is possible to conclude that the score requires attention in its treatment as a document and that there is a need to make improvements in the catalogs and in the indexing process, which aims to standardize their representation and recovery.
\end{abstract}

Keywords: Representation and information retrieval. Musical information. Musical score. Score indexing. Library catalogs.

InCID: R. Ci. Inf. e Doc., Ribeirão Preto, v. 11, n. 1, p. 150-173, mar./ago. 2020.

DOI: 10.11606/issn.2178-2075.v11i1p150-173 


\section{Introdução}

A partitura musical é considerada uma forma de representar a música, podendo ser materializada em papel físico ou no âmbito digital.

Por consistir em uma informação de cunho muito específico e para um público ainda mais restrito, é necessário receber um tratamento adequado. Carmo e Conceição (2018) levantam essa questão, apontando a precariedade do tratamento da informação dos acervos especializados, principalmente os direcionados para música, quando oriundos de uma análise documental superficial, escassa e inadequada. Assim, sua organização é, por si só, complexa, necessitando de medidas específicas para o seu tratamento.

Matos (2007) contextualiza, ressaltando que há muitas inconsistências na representação e recuperação dos sistemas que possuem no acervo a partitura musical, tendo como principal fator o tratamento dessa informação. Por isso, Antonio (1994) enfatiza a necessidade de desenvolver estudos que visem a conhecer e sistematizar as condições da organização da informação musical.

Os catálogos especializados possuem especificações por causa da partitura e, por isso, é importante que haja um tratamento adequado para eles. Dessa maneira, é preciso investigar como a partitura musical está sendo representada e recuperada, dentro dos catálogos especializados, observando-se a sua organização e se há utilização de algum tipo de linguagem definida.

A pesquisa tem como objetivo analisar os catálogos online de bibliotecas que possuem a partitura musical no acervo, a fim de observar a representação documentária dessas partituras, sobretudo sua indexação e como elas estão sendo recuperadas nesses catálogos.

A proposição está em examinar como são realizadas a representação e a recuperação de partituras, através de simulações de busca e navegação dos catálogos, verificando se existe algum tipo de uso de vocabulário controlado. 


\section{Partitura musical: aspectos da representação e recuperação nos catálogos de bibliotecas especializadas em música}

Cardoso (1996) assevera que a música é a arte de combinar sons e silêncio. Através dela é possível expressar sentimentos e emoções, por meio de sons ordenados, variando o seu significado de acordo com cada pessoa e forma particular.

Antes da escrita, segundo Souza e Souza (2014), a música era transmitida apenas via oral. No século IX, os cultos religiosos começaram a usar canções, sendo necessário, dessa forma, escrever as letras dessas músicas para que não fossem esquecidas. Em muitas delas, certos símbolos acompanhavam os textos.

Gandelman (2003, p. 1) explica que, a partir da criação desses símbolos, surge a notação musical, uma ferramenta para ler e escrever a música. Ainda de acordo com a autora, a notação musical corresponde à “[...] representação gráfica dos sons e das instruções para tocá-las feito sobre o papel."

Conforme Silva (2017), a notação musical, conhecida na literatura internacional como Common Practice Music Notation (CPMN), “[...] representa a música (enquanto texto), partindo de um sistema de símbolos da música ocidental de mais de 400 anos" (SILVA, 2017, p. 52).

Segundo McLane (1996), a partitura possui características e funções, servindo como instrução e orientação para execução da sua obra musical, sendo uma forma de padronização para os músicos. Ela é escrita com o intuito de produzir sons, mas enfrenta a limitação de não haver qualquer notação para as qualidades dos sons ou de instruções verbais colocadas diretamente na partitura.

Existem exceções na partitura, como os instrumentos com notação própria, que são tablaturas produzidas especificamente para aquele instrumento e, por isso, não podem ser utilizadas em outro. A sua elaboração se dá através de transcritores, os quais têm como objetivo a preservação escrita da música.

McLane (1996) ressalta que a partitura pode ser considerada tanto como um documento gráfico como um texto, devido às suas características icônicas e simbólicas.

Entretanto, a partitura não foi criada para ser um relato completo de tudo o que foi apresentado em uma performance musical; ela é específica e possui variações. Dificilmente a 
qualidade sonora, incorporada na performance, que não exige qualquer especificação, será nela descrita, pois são características inerentes aos instrumentos musicais (MCLANE, 1996).

Os sistemas de notação musical existem há séculos. Para Zampronha (2000, p. 21), “[...] a notação musical ideal é aquela capaz de registrar e comunicar a informação musical o mais exatamente possível” (apud CALDAS, 2018, p. 29).

Atualmente, o mais usado como partitura é o sistema gráfico denominado pauta ou pentagrama, que emprega os símbolos escritos sobre uma pauta de cinco linhas paralelas e equidistantes, com quatro espaços apresentados da mesma forma.

Caldas (2007) considera a partitura como uma função importante na área da música. O objetivo está em “[...] restituir a música que nela está representada, possibilitando a reinterpretação da música de um determinado tempo e local em outra época" (CALDAS, 2007, p. 26).

Segundo Souza e Souza (2014), na partitura, há elementos descritivos que podem ser verificados em sua folha de rosto ou no próprio cabeçalho, sendo possível identificar outras informações, como o instrumento musical, o tipo de composição, a época, o copista, o arranjador, as notas e símbolos.

As autoras ainda assinalam que as informações contidas nas partituras frequentemente não estão evidentes, acarretando dificuldades em seu tratamento documental e em sua organização. Por isso, é imperioso que se tenha conhecimento em música para obter essas informações (SOUZA; SOUZA, 2014).

Sadie (1997) considera a partitura como

[...] forma de música escrita ou impressa, que abriga todo um conjunto de elementos da notação musical, de maneira a representar visualmente a coordenação musical, garantindo com maior ou menor precisão a sua execução. (SADIE, 1997, p. 702).

Há diversos tipos de partituras musicais, sendo que todas são para um tipo de instrumento diferente e, por isso, possuem especificações distintas. A partir de Bordonau e Petrescu (2011, p. 32), foi criado o quadro apresentando os diversos tipos de partitura e as suas funções (Quadro 1). 


\begin{tabular}{|c|c|}
\hline Partitura condensada & $\begin{array}{l}\text { Aparecem apenas as partes musicais mais } \\
\text { importantes, no menor número possível de } \\
\text { pentagramas, organizadas por seções } \\
\text { instrumentais; }\end{array}$ \\
\hline Partitura de bolso & $\begin{array}{l}\text { Partitura em tamanho reduzido, em } \\
\text { princípio, não destinado para execução; }\end{array}$ \\
\hline Partitura de coro & $\begin{array}{l}\text { Partitura de obra de canto, que mostra } \\
\text { somente as partes do coro, com } \\
\text { acompanhamento, se houver arranjo para } \\
\text { instrumento de teclado; }\end{array}$ \\
\hline Partitura fechada & $\begin{array}{l}\text { Partitura de música na qual aparecem todas } \\
\text { as partes, no menor número possível de } \\
\text { pausas, com geralmente dois instrumentos, } \\
\text { como em hinos; }\end{array}$ \\
\hline Partitura incompleta & $\begin{array}{l}\text { Esboço feito por um compositor para uma } \\
\text { obra destinada ao conjunto, ressaltando em } \\
\text { poucas pautas as características principais da } \\
\text { composição; }\end{array}$ \\
\hline Partitura vocal & $\begin{array}{l}\text { Apresenta todas as partes vocais com o } \\
\text { acompanhamento, caso haja arranjo para } \\
\text { instrumentos de teclado; }\end{array}$ \\
\hline $\begin{array}{c}\text { Partitura do regente, pianista, } \\
\text { violinista e outras }\end{array}$ & $\begin{array}{l}\text { Partitura para um instrumento determinado, } \\
\text { no âmbito de uma obra para conjunto, com } \\
\text { guias para outros instrumentos destinados a } \\
\text { serem usados pela pessoa que toca o } \\
\text { instrumento e, ao mesmo tempo, rege a } \\
\text { execução da obra; }\end{array}$ \\
\hline Partitura para teclados e harpa & $\begin{array}{l}\text { Partitura que tem duas pautas: uma para a } \\
\text { mão esquerda e outra para a mão direita, } \\
\text { pois as duas mãos trabalham separadamente } \\
\text { para a produção dos sons, conseguindo a } \\
\text { harmonização da música; } \\
\text { Em partituras para piano a quatro mãos, a } \\
\text { página esquerda corresponde ao pianista } \\
\text { sentado à esquerda e a página direita } \\
\text { corresponde ao pianista sentado à direita do } \\
\text { piano; }\end{array}$ \\
\hline $\begin{array}{c}\text { Partituras para violão, flauta } \\
\text { etc. }\end{array}$ & $\begin{array}{l}\text { Exigem que as duas mãos trabalhem em } \\
\text { conjunto, pois esses instrumentos precisam } \\
\text { de apenas uma única pauta em suas } \\
\text { partituras. }\end{array}$ \\
\hline
\end{tabular}

Fonte: Adaptado de Bordonau e Petrescu (2011, p. 32)

Caldas (2018) explora, na Figura 1, a comunicação no processo da música. O compositor utiliza a codificação para compor a notação musical (partitura). O intérprete, por sua vez, usa a decodificação para interpretar a notação musical, compreender a partitura e tocar a música. Desse modo, o compositor é a fonte original da música, o criador; a notação musical se torna o canal por onde a mensagem perpassa até chegar ao intérprete, o qual constitui o receptor. A partir do momento que o receptor interpreta a partitura, ele cria uma nova mensagem, com base em sua interpretação e entendimento da partitura, gerando um ciclo de informação. 
Figura 1 - Processos da música

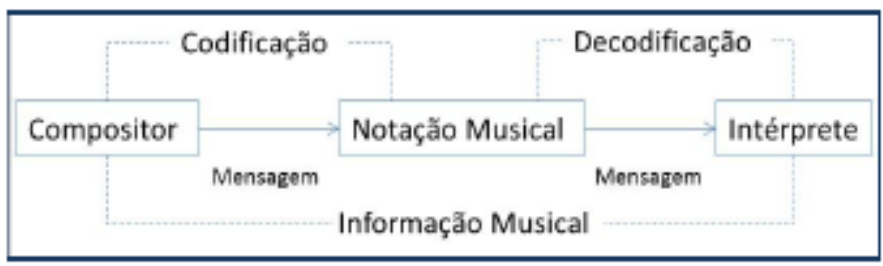

Fonte: Adaptado de Zampronha, 2000 (apud CALDAS, 2018)

Assim, é possível relacionar Música e Ciência da Informação como áreas de conhecimento, principalmente durante a organização e o tratamento informacional de documentos musicais. Barros e Café (2016) ressaltam a relação entre essas áreas, explicando que a música, como documento, pode ser inserida em algum tipo de sistema de informação. Caldas (2018) complementa que, nessa relação, para se incorporar em um sistema de informação, é preciso que a música passe por um tratamento adequado; porém, esse processo vai ser realizado a partir da organização e do uso pelos usuários nas bibliotecas, centros de documentação especializados ou não, na web e em outros tipos de registros musicais.

Lam (2010), desse modo, propõe um modelo de organização do conhecimento para o domínio da música, começando inicialmente com a diferenciação dos conceitos de informação musical e conhecimento musical. O primeiro é considerado como geral, empregado em discussões e fazendo referência a algo que pode ser manipulado e organizado, enquanto o segundo pode ser definido como particular, o qual tem o seu significado em contexto de práticas sociais específicas.

Silva (2017) acrescenta que o processo de organização da informação musical envolve a digitalização e a catalogação de partituras e gravações das coleções, incluindo composições e arranjos manuscritos.

Caldas (2018), por sua vez, enfatiza que as atividades de organização da informação são oriundas das operações do tratamento da informação que estão ligadas à representação temática e do seu conteúdo, seguidas do armazenamento para a recuperação, de acordo com o desejo do usuário.

Segundo Guimarães (2012), o Tratamento Temático da Informação (TTI) refere-se especificamente à análise, descrição e representação do conteúdo dos documentos, com vistas à sua recuperação posterior. 
Para Santos (2011), a indexação é atividade de integrante do TTI, a qual tem a finalidade de extrair termos representativos do assunto de documento, de sorte a referenciar para uma melhor recuperação.

Vieira (1988) considera a indexação como uma técnica de análise de conteúdo que condensa a informação significativa de um documento, através da atribuição de termos, criando uma linguagem intermediária entre o usuário e o documento (VIEIRA, 1988).

O processo de indexação, na visão de Fujita (2003), é dividido em dois estágios: o primeiro é analítico, consistindo na compreensão do texto como um todo, utilizando a identificação e a seleção de conceitos; o segundo estágio é o da tradução, efetuado por meio da representação dos conceitos por termos.

Conforme a Associação Brasileira de Normas Técnicas (1992), a identificação de conceitos é realizada após o exame do documento, quando o indexador deverá seguir uma abordagem sistemática, através de questionamentos, a fim de poder identificar quais os conceitos são essenciais na descrição do assunto.

Fujita (2013) complementa a ABNT (1992), assinalando que a abordagem sistemática é um questionamento que o indexador realiza para melhor extrair conceitos, enquanto estiver analisando o texto. Entretanto, literatura publicada e a $\mathrm{ABNT}$ não esclarecem se essa abordagem sistemática significa um método de identificação de conceitos e nem se os procedimentos estão definidos (ABNT, 1992; FUJITA, 2013).

Esse exame do documento feito pelo indexador está ligado diretamente com a leitura documentária, a qual, segundo Alves (2017), é o processo destinado a identificar os conceitos de um texto científico, que pode ser feito baseando-se em estratégias de exploração de estruturas textuais e de uma abordagem usada de maneira sistemática para explicitar os conceitos.

Quanto à atribuição de conceitos como forma de representação passível de ser recuperada posteriormente, Guim (2016) explica que a recuperação da informação ocorre quando há compatibilidade entre a representação da necessidade de busca e a representação do conteúdo temático dos documentos.

Em uma biblioteca universitária e especializada, o processo de representação documentária é realizado por meio da atribuição de termos que representarão o material dentro do acervo, da melhor maneira possível. Esse processo de seleção, escolha, atribuição e definição 
dos termos é crucial, concretizando-se por meio de uma linguagem de indexação já estabelecida (FUJITA, 2013).

Para Alvarenga (2003), quando o profissional procura representar o conteúdo dos documentos, há inicialmente a identificação dos conceitos, a qual mais tarde resultará em uma representação secundária, visando à busca dos usuários no sistema de informação.

Por se referir a partitura, é necessário ter um tratamento adequado e específico. Não se trata apenas de texto, mas dos símbolos presentes nas partituras, que as tornam visuais. Por isso, um ponto importante está no contexto sociocognitivo do indexador, que, segundo Fujita (2013), é determinante "[...] para a diminuição da subjetividade no sentido de que quanto mais compreensão tiver do processo e da subjetividade nele envolvido, mais condições ele terá de resolver os problemas." Por isso, nesse cenário, é necessário que o indexador tenha um conhecimento prévio sobre a área de música (FUJITA, 2013).

Dodebei e Grau (2003) ressaltam que a organização do material musical em bibliotecas deve ocorrer de modo que o bibliotecário se alie ao músico. O conhecimento, nessa especificidade, é essencial para se poder selecionar e interpretar as informações de forma coerente, a qual auxilie os usuários no estabelecimento de estratégias de busca (DODEBEI; GRAU, 2003).

Nesse sentido, Dodebei e Grau (2003) definem os procedimentos que devem ser adotados para organizar os acervos especializados em música, dentro das bibliotecas: é essencial que haja padronização dos elementos descritivos, pois esta afetará a busca e a recuperação da partitura. Por isso, é importante observar com atenção os termos atribuídos e selecionados nos pontos de acesso, incluindo a tradução e o controle dos termos, em diversas línguas.

As formas e gêneros musicais, listas de autorias e tipos de instrumentos são elementos fundamentais para a padronização. Dessa maneira, requerem que haja investigação, quando necessário, em fontes de pesquisa especializadas e consagradas, como o Dicionário Grove (DODEBEI; GRAU, 2003).

De acordo com Dodebei e Grau (2003), as decisões quanto à descrição dos elementos devem ser tomadas no início do processamento técnico. Os autores explicam que, nesse caso, está a adoção ou não de nomes em português para determinados instrumentos ou o tipo de grafia a ser adotada para os nomes dos compositores que são escritos em alfabetos diferentes. 
Assim como nos livros e outros materiais, apontam Dodebei e Grau (2003), o bibliotecário, responsável pelo processamento técnico, precisa consultar as normas estabelecidas para a tomada de decisões, no momento da indexação da partitura. Nesse caso, a norma disponível especificamente para esse tipo de material é a do AACR2, podendo ser consultados e importados, também, os registros da Biblioteca Nacional do Rio de Janeiro (BN) e da Library of Congress (LC).

Myers (1995) complementa Svenonius (1994), mostrando as especificidades das características da música e as dificuldades envolvidas em sua catalogação e indexação. A autora destaca o conceito de assunto, em música, o qual pode variar de acordo com o suporte em que está inserido. Ela assevera ainda que, com isso, resulta a inexistência de padronização na identificação de título e responsabilidade, devido à redundância de informações da representação descritiva.

Segundo Smiraglia (2001, 2002), a obra é considerada o conceito-chave para a recuperação da informação musical. Atualmente, o uso do título é o que mais se aproxima dessa perspectiva. $\mathrm{O}$ autor afirma que o seu significado é uma função da percepção humana, podendo variar de acordo com aspectos culturais.

Gil Leiva $(1999,2008)$ destaca que a indexação e a recuperação são duas “caras” de uma mesma moeda. Fujita e Gil Leiva (2014) acrescentam que é cada vez mais frequente dispor de opções de navegação e consulta dos vocabulários controlados, nas mesmas telas onde se executam as buscas de informação nos catálogos e bases de dados (GIL LEIVA, 1999, 2008; FUJITA; GIL LEIVA, 2014). 


\section{Procedimentos metodológicos}

Os procedimentos metodológicos baseiam-se em Gil (2007), para quem a finalidade da pesquisa exploratória e analítica é ampliar o conhecimento a respeito de um determinado fenômeno.

Jung (2003) considera a pesquisa exploratória como uma coleta de dados e informações sobre um fenômeno de interesse, dessa forma, podendo inspirar e sugerir uma hipótese explicativa.

Para concretizar este estudo, foram selecionadas quatro bibliotecas que possuem acervos especializados em música: Biblioteca do Conservatório de Tatú́, Biblioteca do Instituto de Artes (IA) da Universidade de Campinas (UNICAMP), Biblioteca do Instituto de Artes da Universidade Estadual Júlio de Mesquita Filho (UNESP) e o catálogo de Partitura da Universidade de São Paulo, pertencente ao SiBi USP; em função dessa seleção, foram realizadas simulações de busca e pesquisa, a fim de observar e analisar como as partituras estão representadas e são recuperadas, dentro do catálogo das bibliotecas.

Esta pesquisa foi dividida em duas partes. A primeira consiste em analisar os registros das partituras, a partir de simulações de busca, visando a observar como elas estão sendo representadas dentro do catálogo. A segunda fase da pesquisa destina-se a analisar como é a recuperação, com base na pesquisa avançada por assunto.

As simulações de busca foram realizadas no modo avançado, de sorte a ensejar uma análise mais aprofundada. Nessa perspectiva, os termos "partitura" e "Mozart" foram combinados: o primeiro termo representa o tipo do documento e objeto de estudo deste trabalho; o segundo foi escolhido por ser um compositor muito conhecido, chegando a ser identificado até mesmo por usuários que não são da área da música.

Os termos foram empregados na barra de busca avançada, para se efetuar a pesquisa e se analisar como os arquivos dentro dos sites estão sendo representados e recuperados. Os quatro catálogos possuem partituras no seu acervo físico. Cada catálogo tem a sua própria maneira de tratar o documento, representar as partituras e as indexar nos sites. Esse processo reflete diretamente a sua busca e a sua recuperação pelo usuário. 
Desse modo, as simulações de busca permitem observar e analisar a possibilidade de existência de critérios e especificações dos catálogos, na representação e recuperação das partituras neles.

Com os estudos e a literatura levantada na área da Ciência da Informação e na área da Música, foi possível realizar simulações de buscas nos catálogos especializados e analisar os registros de partituras recuperados.

\section{Análise da representação de partituras musicais por assunto}

Essa análise surgiu de observar os registros das partituras musicais em função das simulações de busca, visando, especificamente, aos termos atribuídos no campo "assunto" e/ou "palavras-chave" e os registros recuperados.

Para realizar a simulação de busca, foi pesquisado na barra de busca avançada o termo composto "Mozart + partitura" (Figura 2).

Figura 2 - Registro da busca no catálogo do Conservatório de Tatuí

\begin{tabular}{|l|}
\hline X3066 - DUO - Violino, Piano / 25.12 .8 \\
\hline MOZART, Wolfgang Amadeus (1756-1791). Concerto Nr. 5 in \\
Orquestra]. EDIÇÃO - Joseph Joachim. New York: Simrock, c1 \\
NoZART \\
Notas de conteúdo: \\
- Redução para violino e piano \\
Palavras-chave: \\
DUO - VIOLINO. PIANO.
\end{tabular}

Fonte: http://cdmcc.phlnet.com.br

A Figura 2 apresenta o Catálogo da Biblioteca do Conservatório de Tatuí, o qual adota um catálogo intitulado PHL.net Opac. Por se tratar de partituras, o próprio catálogo é especializado e voltado para a área de música. Na página principal, há instruções de como se proceder a uma busca.

O site é estático e enrijecido, os resultados expostos consistem no próprio registro, não existe nenhum nível mais profundo para ser acessado, dificultando a análise do registro da partitura (Figura 2). 
Apesar de os metadados do registro não estarem disponíveis (Figura 2), é possível ver que o documento foi recuperado pelo compositor, pelo título, pelas notas de conteúdo e pelas palavras-chave, mostrando que há compatibilidade entre a representação da necessidade da busca e os termos da representação do conteúdo temático dos documentos (GUIM, 2016).

As palavras-chave, apresentadas na Figura 2, são referentes ao gênero musical e ao tipo de instrumento musical, sendo considerados elementos descritivos essenciais na padronização do processo de indexação de partitura (DODEBEI; GRAU, 2003).

Nesse catálogo, é disponibilizada a busca simples e, a partir dela, é possível filtrar, antes da pesquisa, as "preferências" do usuário. Os campos disponíveis na Figura 3 são idioma, tipo de suporte, tipo de conteúdo, características tidas como importantes para realizar a busca de partituras nos catálogos especializados (SOUZA; SOUZA, 2014).

Figura 3 - Preferências para filtragem de busca

\begin{tabular}{|c|c|c|}
\hline \multicolumn{2}{|c|}{ QPreferências } & \multirow[b]{2}{*}{$\checkmark$} \\
\hline Indices & Desativado & \\
\hline Coleçẫo & Todos & 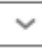 \\
\hline Campos de Dados & Todos & $\sim$ \\
\hline Formato de exibiçã̃o & Completo (Data de Entrada) & $\sim$ \\
\hline Registros por página & 100 & \\
\hline Idioma & Todos & $\checkmark$ \\
\hline Tipo de documento & Todos & $\checkmark$ \\
\hline Tipo de suporte & Todos & $\checkmark$ \\
\hline Tipo de conteúdo & Partitura & 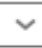 \\
\hline & Concluir & \\
\hline
\end{tabular}

Fonte: http://cdmcc.phlnet.com.br

O catálogo da Biblioteca do Conservatório de Tatuí (Figuras 2 e 3 ) é simples e cumpre o básico necessário para atender os usuários. Entretanto, ainda faltam informações essenciais, como acesso à folha de rosto ou cabeçalho da partitura, de modo a observar informações específicas, como notas, símbolos e arranjos (SOUZA; SOUZA, 2014; SILVA, 2017). 
Figura 4 - Manual do PHL.net Opac

As informaçōes contidas neste campo de dado são indexadas com os seguintes prefixos:

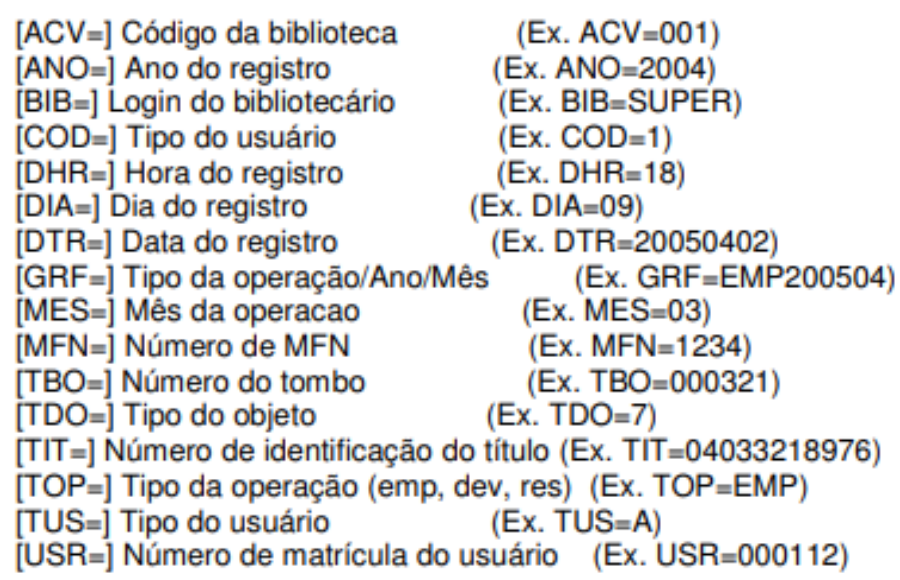

Fonte: http://cdmcc.phlnet.com.br

Nesse catálogo, é disponibilizado um manual explicando como cada campo é indexado e o seu código, seguindo as regras do AACR2 e da NBR 6023 da ABNT (Figura 4), consideradas fontes especializadas de consultas consagradas e básicas para o tratamento da partitura (DODEBEI; GRAU, 2003).

Figura 5 - Registro da partitura

241 registros localizados

Titulo: Arias das Óperas de Mozart

Compositor:

Tombo IA: 3984

Tombo BC: 0

N.Chamada: E-2155

Titulo: Arias from Operas / v.1

Compositor: Mozart

Tombo IA: 3970

Tombo BC: 1741

N.Chamada: E-2139

Fonte: https://www.iar.unicamp.br/biblioteca/ 
Na Figura 5, é apresentado o catálogo da Biblioteca do Instituto de Artes (IA) da Universidade de Campinas (UNICAMP). Esse catálogo faz a divisão por videoteca, fonoteca e partituras. Dentro da seção de partituras, há subcategorias divididas em "todos", "compositor" e "título". Dessa forma, eles não possibilitam efetuar uma busca avançada.

Os registros são igualmente estáticos, nesse catálogo (Figura 5). Eles revelam apenas o tombo da biblioteca e o número de chamada. Os termos que representam a partitura no site não estão disponíveis para o usuário acessar; ademais, há registros nos quais faltam informações, como na categoria "compositor". Dessa maneira, o processo de indexação de partituras é desconhecido, sendo impossível saber, através do catálogo, o grau de indexação, a existência de inconsistências na representação e recuperação das partituras nos sistemas e os termos atribuídos para representar e recuperar as partituras (MATOS, 2007), diferentemente das informações essenciais estabelecidas por McLane (1996), Dodebei e Grau (2003), Souza e Souza (2014), Silva (2017) e Caldas (2018).

Apesar da falta dessas informações, foi formulada uma hipótese, a partir da observação do catálogo, na Figura 5, de que os registros recuperados possuem informações nos campos "título" e "compositor" condizentes com o termo utilizado na busca. Assim, o termo pode ter sido atribuído para representar essas partituras e, por isso, teria sido recuperado pelo sistema (SMIRAGLIA, 2001, 2002). 
Figura 6 - Registro da partitura no catálogo da UNESP

$\begin{array}{ll}\begin{array}{ll}\text { Detalhes } \\ \text { Título }\end{array} & \begin{array}{l}\text { Soprano Mozart arias [para soprano e piano] } \\ \text { Autor }\end{array} \\ & \begin{array}{l}\text { Rolfgang Amadeus Mozart 1756-1791. > }> \\ \text { Richard Walters }>\end{array} \\ \text { Assuntos } & \text { Música para canto e piano - Partituras > }> \\ & \text { Canto e piano - Partituras > } \\ & \text { Opera (arias) - Partitura > } \\ \text { Descrição } & \begin{array}{l}\text { Pupile amate - Zeffiretti lusinghieri - walche wo } \\ \text { tardar - Barri, batti, o bel Masetto - Vedrai, carin }\end{array} \\ \text { lagrime - Ach, ich fühl's } \\ \text { Títulos relacionados } & \begin{array}{l}\text { Série: (The vocal library) } \\ \text { Editor }\end{array} \\ \text { Milwaukee, WI : Hal Leonard } \\ \text { C1993. } \\ \text { Formato criação } & \begin{array}{l}\text { 1 partitura } 62 \text { p.) + Acompanha CD } \\ \text { Idioma }\end{array} \\ \text { Identificador } & \begin{array}{l}\text { ISBN: } 9780793562398 \\ \text { Catálogo Athena Unesp }\end{array} \\ \text { Fonte } & \text { Fonte: https://pesquisa.biblioteca.unesp.br }\end{array}$

No catálogo da UNESP, é possível pesquisar e realizar a busca simples ou avançada em todas as bibliotecas, em todos os câmpus, ou em uma biblioteca de um câmpus específico. Nesse caso, foi realizada a busca na biblioteca do Instituto de Artes, com os termos "partitura" + "Mozart" no assunto.

No registro (Figura 6), a partitura é representada no campo "assunto" e possui um único termo, que condiz com o que foi empregado na busca. Porém, ele faz referência à tipologia do material e para que instrumento está voltado. O termo "Mozart", por exemplo, é apresentado como "título" e "autor", sendo recuperado por eles, mas não é atribuído no campo "assunto".

A despeito de mostrar que há uma indexação e recuperação pelo assunto, pelo título e pelo compositor, no catálogo (Figura 6), os termos escolhidos não são completamente pertinentes, pois não conseguem representar adequadamente a obra; faltam termos para complementar o registro, como, por exemplo, o termo "Mozart". A partir disso, é possível observar que, quando a análise e o tratamento da informação são superficiais, escassos e inadequados, há inconsistências na representação e recuperação. Mesmo que o catálogo consiga exercer a sua função, ainda é insuficiente (MATOS, 2007; CARMO; CONCEIÇÃO, 2018). 
Figura 7 - Registro da partitura no catálogo da USP

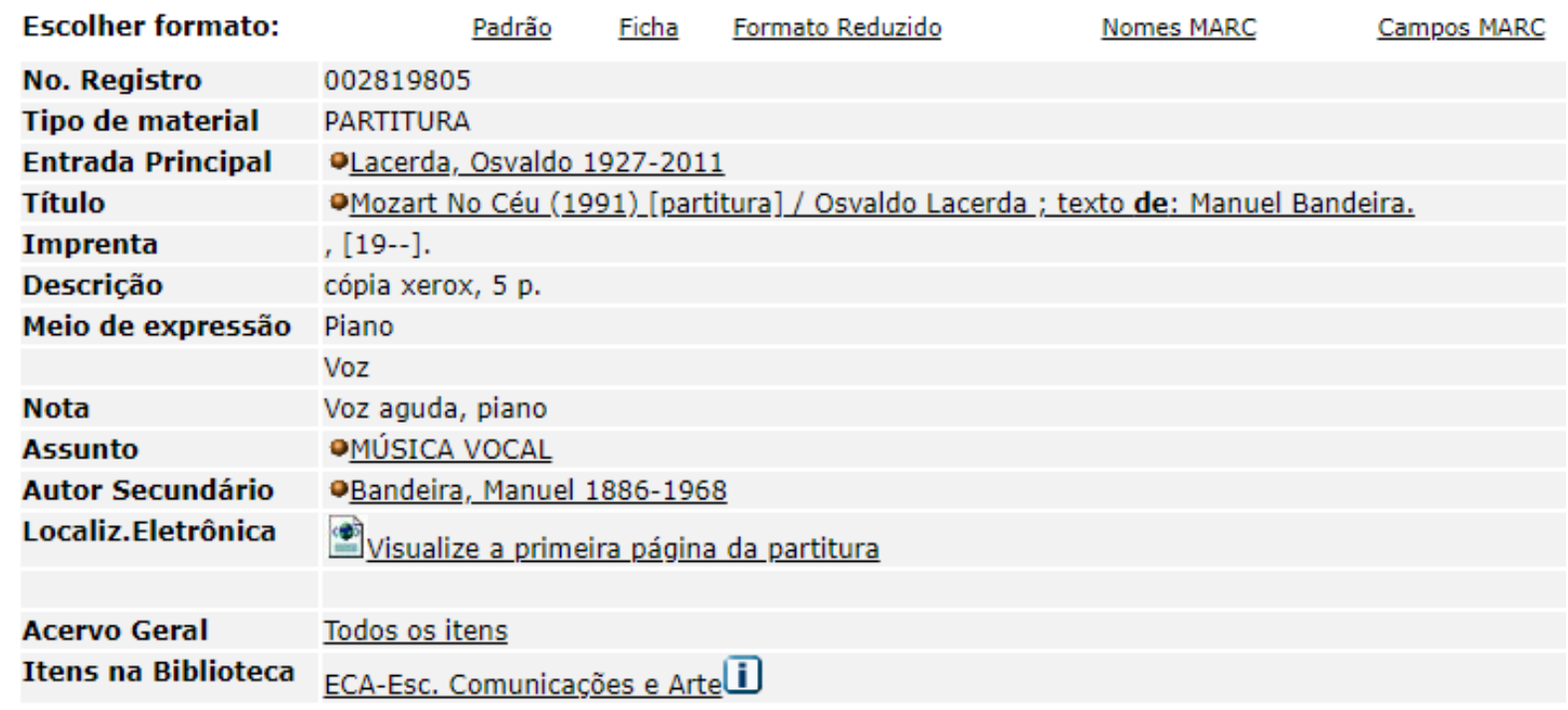

Fonte: http://colecoes.sibi.usp.br/partituras/

No catálogo da USP, na Figura 7, a princípio, não há como realizar uma busca avançada, mas, após a pesquisa, é possível filtrar e refinar a busca. No registro, a primeira página e a folha de rosto da partitura são deixadas disponíveis digitalmente para acesso, uma característica importante para o catálogo e para o usuário conseguir visualizar como a partitura é, fisicamente (SOUZA; SOUZA, 2014).

Nesse registro, é possível observar que os termos pesquisados estão atribuídos no tipo de material e no título. No campo "assunto", não há relação com os termos buscados, de modo que a sua representação não é adequada e afeta diretamente a recuperação da partitura, não apresentando compatibilidade entre o termo buscado e a representação atribuída no conteúdo temático da partitura (GUIM, 2016). Nele, é possível encontrar o registro também no formato MARC, assim como há como encontrar o registro, nesse mesmo formato, na Biblioteca Nacional (DODEBEI; GRAU, 2003). 


\section{Análise da recuperação de partituras musicais por assunto}

Nessa fase, a análise é feita por meio da recuperação das partituras musicais, a partir das simulações de busca realizadas nos catálogos.

Figura 8 - Recuperação das partituras no Conservatório de Tatuí

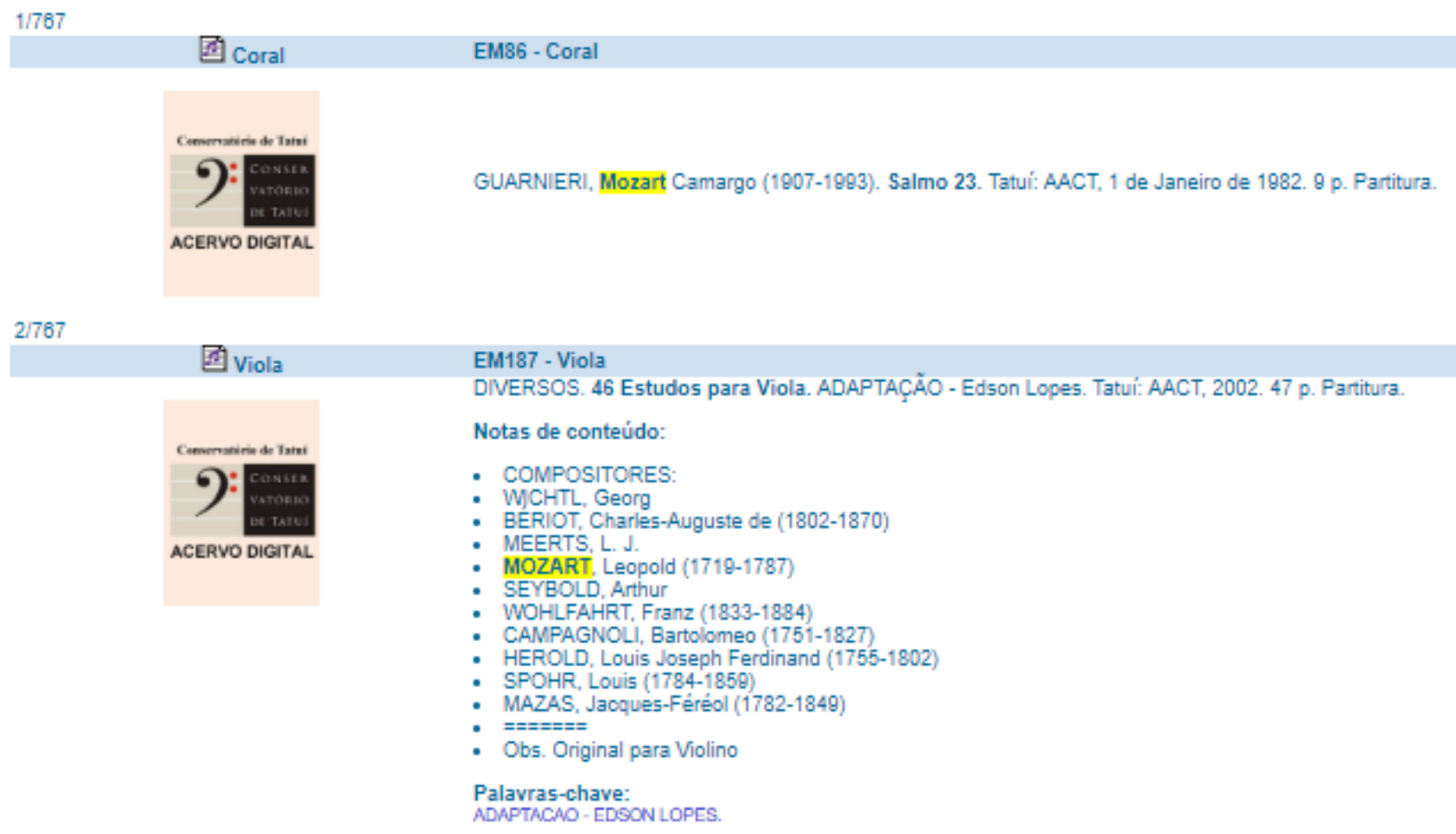

Fonte: http://cdmcc.phlnet.com.br

A busca no catálogo do Conservatório de Tatuí apresentou 767 registros como resultados. No "status" da partitura (Figura 8), tem-se a disponibilidade da partitura no local e a sua localização exata dentro do acervo.

A maioria dos registros foi recuperada pelo título, compositor e notas de conteúdo. Pela análise, no catálogo, pode-se perceber que os termos "Mozart" e "partitura" não são atribuídos nas palavras-chave ou em algum outro campo de assunto, faltando informações necessárias para deixar o registro completo e padronizar a indexação da partitura (DODEBEI; GRAU, 2003; SOUZA; SOUZA, 2014). Mesmo sendo definido o tipo de documento, o catálogo recupera outros tipos de documento, como áudios, CDs e livros (Figura 8). 
Figura 9 - Recuperação das partituras no catálogo da UNICAMP

\author{
Pesquisa de Partituras \\ Você buscou por: mozart \\ 241 registros localizados
}
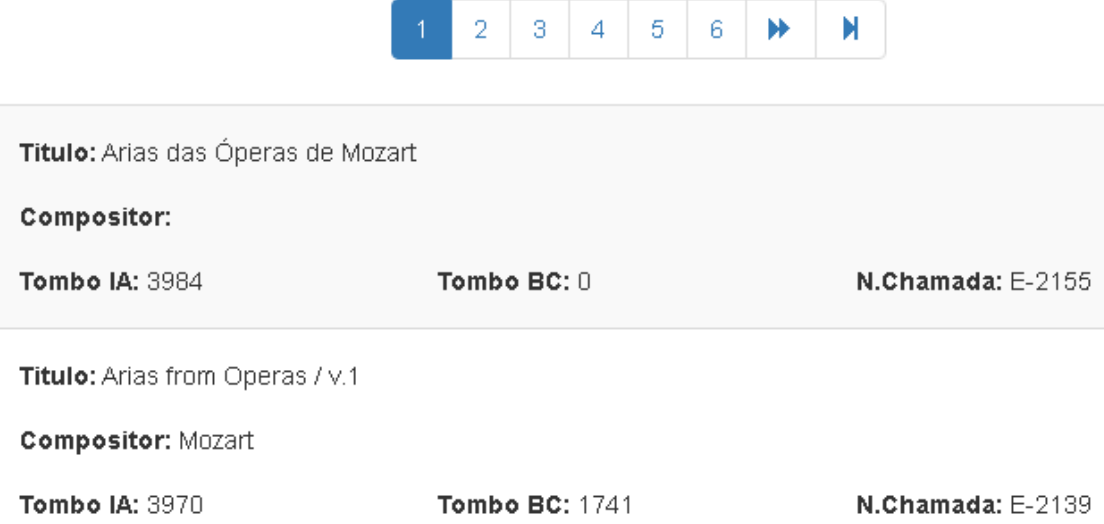

Fonte: https://www.iar.unicamp.br/biblioteca/

A busca, na Figura 9, foi feita por meio dos termos "Partituras + Mozart", mas não obteve nenhum resultado. Por isso, foi escolhido para realizar uma nova busca apenas o termo "Mozart", obtendo 241 registros.

No catálogo da Biblioteca da UNICAMP (Figura 9), verifica-se somente a localização da partitura dentro do acervo físico. Não há como acessar o registro; assim, não se pode saber quais foram os termos atribuídos na representação das partituras e a compatibilidade com a recuperação de uma busca, sendo um grande problema para o usuário encontrar a informação e isso pode levar o mesmo a se perder dentro do catálogo. Analisando-se os registros recuperados e, a partir de Smiraglia (2001, 2002), criou-se a hipótese de que algumas das partituras foram recuperadas por conterem no título e no compositor o mesmo termo buscado. O título é considerado o que mais se aproxima do conceito-chave para a recuperação da informação musical (Figura 9). 
Figura 10 - Recuperação das partituras no catálogo da UNESP

Soprano Mozart arias [para soprano e piano]
Wolfgang Amadeus Mozart 1756-1791. Robert L. Larsen 1934-; Richard Walters
c1993.
Disponivel em São Paulo - Instituto de Artes Multimídias (CD 4846) >

Fonte: https://pesquisa.biblioteca.unesp.br

No catálogo da UNESP, através da biblioteca do Instituto de Artes, quando é feita a busca avançada, com os termos "Mozart + partitura", aparecem apenas 5 registros. Paralelamente, para fazer uma comparação, a busca simples, nessa mesma biblioteca, somente com o termo "partitura", recupera 143 registros. E, quando é pesquisado só o termo "Mozart", são recuperados 710 registros. A partir disso, pode-se considerar a existência de uma grande discrepância entre a quantidade de registros recuperados nas buscas (Figura 10).

Na busca avançada, na Figura 10, obtiveram-se 5 registros, recuperados pelo título e pelo compositor. No campo "assunto", os termos pesquisados não condizem com os termos atribuídos ao documento, havendo uma incompatibilidade entre eles e faltando informações necessárias para padronizar a partitura, não se disponibilizando a informação para o usuário conseguir encontrar e causando a precariedade do acervo (SOUZA; SOUZA, 2014; GUIM, 2016; CARMO; CONCEIÇÃO, 2018). 
Figura 11 - Recuperação das partituras no catálogo da USP

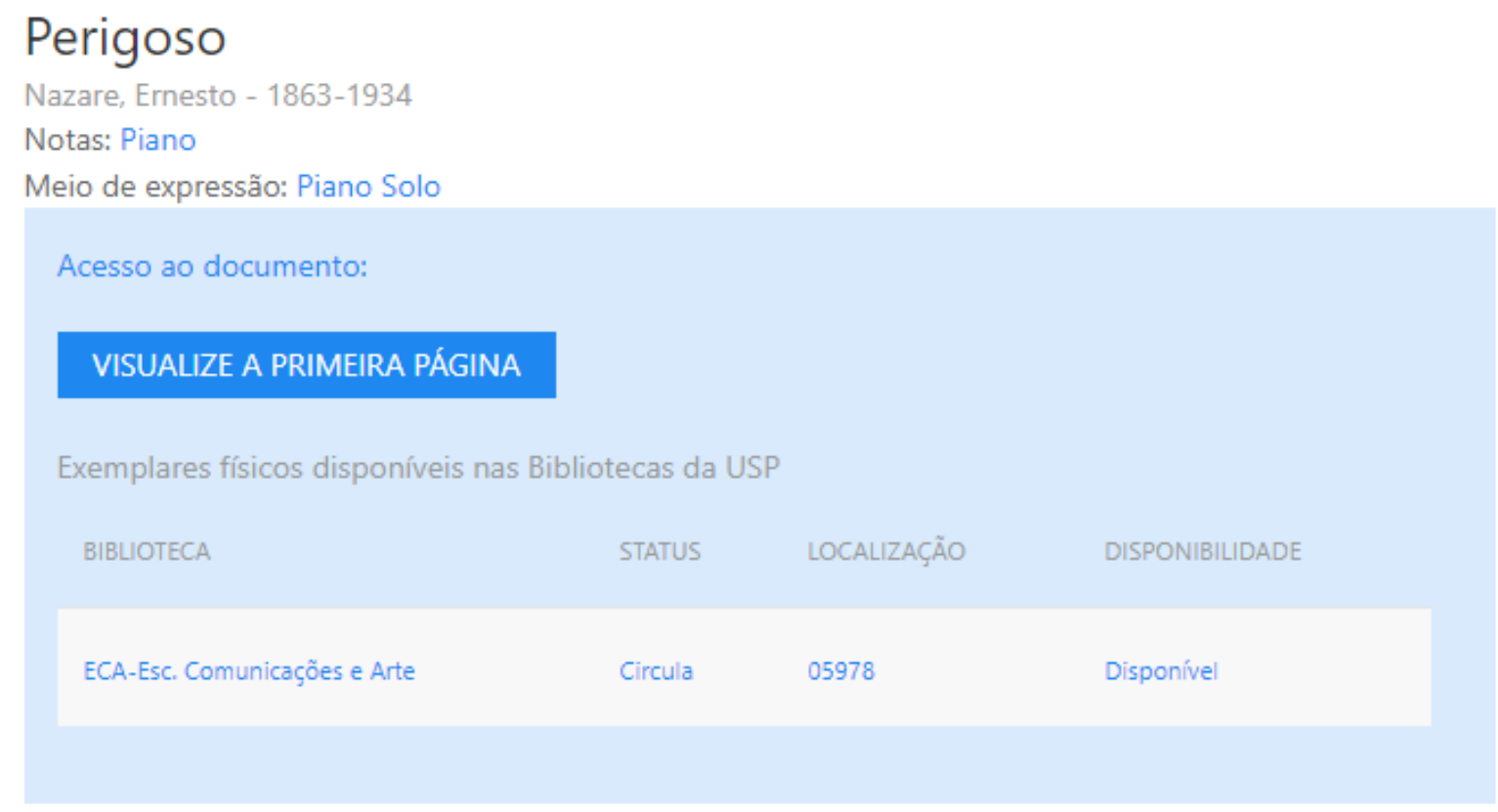

Fonte: http://colecoes.sibi.usp.br/partituras/result.php?search\%5B\%5D="Mozart"+\%2B+"partitura"

No catálogo da USP, na Figura 11, foram pesquisados os termos "Mozart" + "partitura", obtendo-se 20.547 registros recuperados; nesse sentido, esse pode ser considerado como aquele que dispõe do maior número recuperado, entre todos os catálogos analisados.

Na Figura 11, pode-se perceber que são apresentadas a localização da partitura, a existência de exemplares físicos na biblioteca e a primeira página da partitura escaneada, disponível para visualização, sendo essa última um elemento essencial para se conseguir visualizar como ela é, fisicamente (SOUZA; SOUZA, 2014; SILVA, 2017).

Analisando-se esses registros (Figura 11), é possível constatar que muitas partituras não têm relação com o termo pesquisado "Mozart", mas foram recuperadas apenas pelo termo "partitura", ou seja, o tipo de documento. Observando-se as partituras que têm algum termo "Mozart" atribuída no registro, notou-se que elas estão atribuídas no título e na composição, podendo ter sido recuperadas a partir deles.

Apesar de esses campos serem elementos básicos para se ter conhecimentos sobre uma partitura, ainda são insuficientes, pois não conseguem representar adequadamente uma partitura, necessitando de informações fundamentais, como tipo de instrumentos, sua simbologia, arranjador, notas, formas e gêneros musicais, copistas, tipo de composição, se possuem notação própria etc. (MCLANE, 1996; DODEBEI; GRAU, 2003; SOUZA; SOUZA, 2014). 


\section{Conclusões}

Após analisar a literatura levantada sobre as partituras musicais e a sua relação com a Ciência da Informação e realizar as simulações de buscas, nos catálogos da Biblioteca do Conservatório de Tatuí, da Biblioteca do Instituto de Artes da UNICAMP, da Biblioteca do Instituto de Artes da UNESP e no catálogo de partituras da USP, pode-se concluir que, quando a partitura não recebe um tratamento da informação adequado, isso gera inconsistências e incompatibilidades na representação e, por consequência, na recuperação. Esse processo prejudica o usuário, que, por sua vez, não consegue encontrar a partitura sobre a qual está pesquisando, e a própria biblioteca, podendo-se perder a partitura no limbo da internet.

Observando-se os catálogos das bibliotecas, ficou visível a necessidade em melhorar a disponibilização das informações e a sua indexação. Alguns dos catálogos não permitem acessar os detalhes dos registros, tornando impossível saber quais foram os termos atribuídos na representação das partituras e afetando a análise, na recuperação das informações.

Os registros que possibilitam analisar o campo "assunto" possuem termos que não condizem com os termos utilizados na busca. Ora, a partir da recuperação dos registros, podese perceber que, na maioria das bibliotecas, os termos buscados correspondem aos termos atribuídos nos campos do "título", "compositor", "autor" e "tipo de instrumento musical". Assim, a recuperação dos registros está sendo feita por meio desses campos, especificamente.

As informações disponibilizadas pelos registros não são adequadas e suficientes para representar a partitura: mesmo apresentando palavras-chave, refinamentos de busca, busca por assunto, ainda não há como saber o modo como os indexadores fizeram esse processo e atribuíram os termos aos documentos.

A partitura é um documento de cunho específico, visual e simbólico, destinado a um público ainda mais singular, exigindo um grau de complexidade, no processo de indexação. Por isso, seu tratamento difere daquele conferido a um texto comum, como livro e artigo. Dessa forma, é imprescindível que o bibliotecário responsável por esse trabalho tenha um conhecimento na área da música, conseguindo ler partituras. 


\section{Referências}

ABNT. NBR 12676: métodos para análise de documentos - determinação de seus assuntos e seleção de termos de indexação. Rio de Janeiro: ABNT, 1992. p. 1-4. Disponível em: https://edisciplinas.usp.br/pluginfile.php/372910/mod_resource/content/1/Norma\%20Brasilen a\%20Indizacion\%20Isidoro\%20Gi1\%20Leiva.pdf. Acesso em: 01 dez. 2019.

ALVARENGA, L. Representação do conhecimento na perspectiva da ciência da informação em tempo e espaço digitais. Encontros Bibli: Revista Eletrônica de Biblioteconomia e Ciência da Informação, Florianópolis, n. 15, 2003. Disponível em: https://periodicos.ufsc.br/index.php/eb/article/view/1518-2924.2003v8n15p18/5233. Acesso em: 20 nov. 2019.

ALVES, R. C. V. Modelo de leitura documentária para indexação de leitura infantil do gênero fábula: esquemas textuais para fundamentação de estratégias metacognitivas. In: FUJITA, M. S. L.; NEVES, D. A. B.; EVEDOVE, P. R. Dal' (org.). Leitura documentária: estudos avançados para indexação. São Paulo: Cultura Acadêmica, 2017. p. 133-156.

ANTONIO, I. Informação e música no Brasil: memória, história e poder. São Paulo, 1994. 285f. Dissertação (Mestrado em Ciência da Informação) - Escola de Comunicações de Artes, Universidade de São Paulo, São Paulo, 1994.

BARROS, C.; CAFÉ, L. M. A. The relevance of music information representation metadata from the perspective of expert users. Transinformação, Campinas, v. 25, n. 3, p. 213-223, 2016. Disponível em: http://periodicos.puccampinas.edu.br/seer/index.php/transinfo/article/view/2077/1772. Acesso em: 19 jun. 2019.

BORDONAU, E. B.; PETRESCU, C. Typology of the musical document: an approach to its study. Bulletin of the Transilvania University of Brasov. Transilvania, v. 4 (54), n. 2, 2011. Disponível em: http://webs.ucm.es/centros/cont/descargas/documento39570.pdf. Acesso em 23 jul. 2020.

CALDAS, S. E. S. Elementos necessários à representação descritiva de partituras: um estudo com as Bachianas Brasileiras n. 1, 2 e 4 de Heitor Villa-Lobos. 2007. Monografia (Bacharelado em Ciência da Informação) - Pontifícia Universidade Católica de Campinas, Campinas, 2007.

CALDAS, S. E. S. Organização e recuperação da informação musical: o incipit como elemento de representação. 2018. Dissertação (Mestrado em Ciência da Informação) Universidade de São Paulo, São Paulo, 2018.

CARDOSO, I. V. Vocabulário controlado para indexação de partitura de música brasileira: proposta de uma estrutura básica. Transinformação, Campinas, v. 8, n. 3, p. 81-96, set./dez., 1996.

CARMO, J. R.; CONCEIÇÃO, V. P. Processamento da linguagem natural do domínio musical: do sentido a gestão terminológica no ambiente e-termos. Informação \& Informação, Londrina, v. 23, n. 3, p. 314-341, set./dez. 2018. 
DODEBEI, V. L. D.; GRAU, I. A. Arquivo musical: a pesquisa no acervo Vera Janacópulos. In: ENCONTRO NACIONAL DE PESQUISA E PÓS GRADUAÇÃO EM CIÊNCIA DA INFORMAÇÃO, 5., Belo Horizonte, 2003. Anais eletrônicos... Belo Horizonte: UFMG, 2003.

FUJITA, M. S. L. A identificação de conceitos no processo de análise de assunto para indexação. Revista Digital de Biblioteconomia e Ciência da Informação. Campinas: v. 1, n. 1, p. 60-90, jul./dez. 2003.

FUJITA, M. S. L. A representação documentária no processo de indexação com o modelo de leitura documentária para textos científicos e livros: uma abordagem cognitiva com o protocolo verbal. Ponto de Acesso, Salvador, v. 7, n. 1, p. 42-66, 2013. Disponível em: https://portalseer.ufba.br/index.php/revistaici/article/view/8135. Acesso em: 07 set. 2019.

FUJITA, M. S. L.; GIL LEIVA, I. Avaliação da indexação por meio da recuperação da informação. Ci. Inf., Brasília, v. 41, n. 1, p. 50-66, jan./abr., 2014.

GANDELMAN, S. Breve história da notação musical. 2003. Disponível em: http://www.musicaeadoracao.com.br/tecnicos/teoria_musical/historia_notacao.htm. Acesso em: 26 jun. 2019.

GIL, A. C. Métodos e técnicas de pesquisa social. 5. ed. São Paulo: Atlas, 2007.

GIL LEIVA, I. La automatización de la indización de documentos. Gijón: TREA, 1999.

GIL LEIVA, I. Manual de indización: teoría y práctica. Gijón: TREA, 2008.

GUIM, V. L. R. O uso de linguagem documentária no âmbito da política de indexação em biblioteca escolar. 2016. 128 f. Dissertação (Mestrado em Ciências da Informação) Universidade Estadual Paulista Júlio de Mesquita Filho, Faculdade de Filosofia e Ciências, Marília, 2016. Disponível em: https://www.marilia.unesp.br/Home/Pos-

Graduacao/CienciadaInformacao/Dissertacoes/guim_vlr_me_mar.pdf. Acesso em: 03 set. 2019.

GUIMARÃES, J. A. C. Correntes teóricas do tratamento temático da informação: uma análise de domínio da presença da catalogação de assunto e da indexação nos congressos de ISKO-España. 2012. Disponível em: http://www.iskoiberico.org/wpcontent/uploads/2014/09/181-194_Guimaraes.pdf. Acesso em: 13 maio 2019.

JUNG, C. F. Metodologia científica: ênfase em pesquisa tecnológica. [s. l.], 2003.

Disponível em: http://www.mecanica.ufrgs.br/promec/alunos/download/metodolo.pdf. Acesso em: 12 jul. 2019.

LAM, M. Towards a "musicianship model” for music knowledge organization. OCLC

System \& Services: International Digital Library Perspectives, v. 27, n. 3, p. 190-209, 2010.

MATOS, A. L. H. Documentação musical: discussão sobre a representação temática de partituras de um enfoque interdisciplinar. 2007. 116 f. Dissertação (Mestrado em Ciência da Informação) - Universidade de São Paulo, São Paulo, 2007. 
MCLANE, A. Music as information. In: CRONIN, B. Annual Review of Information Science and Technology. 37. ed. Medford: Information Today, 1996. p. 295-340.

MYERS, J. A. Music: special characteristics for indexing and cataloguing. The Indexer, v. 19, n. 4 , out. 1995.

SADIE, S. Dicionário Grove de música: edição concisa. Rio de Janeiro: Zahar, 1997. 1048p.

SANTOS, L. B. P. Política de indexação para bibliotecas: relatório. Marília: Faculdade de Filosofia e Ciências, Universidade Estadual Paulista, 2011. (Bolsa do Conselho Nacional de Pesquisa e Desenvolvimento Tecnológico CNPq).

SILVA, J. R. F. Diretrizes para organização de informação musical brasileira. 2017. Tese (Doutorado em Ciência da Informação) - Universidade de Brasília, Brasília, 2017.

SMIRAGLIA, R. P. Musical works as information retrieval entities: epistemological perspectives. In: INTERNATIONAL SOCIETY FOR MUSIC INFORMATION RETRIEVAL CONFERE, Bloomington, 2001. Anais eletrônicos... Bloomington: ISMI, 2001. Disponível em: http://ismir2001.ismir.net/pdf/smiraglia.pdf. Acesso em: 14 maio 2019.

SMIRAGLIA, R. P. Further reflections on the nature of "a work": an introduction.

Cataloging \& Classification Quarterly, v. 33, n. 3-4, p. 1-11, 2002. Disponível em:

http://polaris.gseis.ucla.edu/gleazer/461_readings/Smiraglia.pdf. Acesso em: 14 maio 2019.

SOUZA, B. B. S.; SOUZA, J. C. C. E. Princípios para análise da partitura musical como documento arquivístico. Archeion Online, João Pessoa, v. 2, n. 2, p. 30-54, jul./dez. 2014.

SVENONIUS, E. Access to nonbook materials: the limits of subject indexing for visual and aural languages. Jornal of the American Society for Information Science and Technology, v. 45, n. 8, p. 600-606, set. 1994. Disponível em

http://polaris.gseis.ucla.edu/gleazer/462_readings/Svenonius_1994.pdf. Acesso em: 14 maio 2019.

VIEIRA, S. B. Indexação automática e manual: teoria e prática. 1988. Disponível em: http://revista.ibict.br/ciinf/article/view/298. Acesso em: 10 mar. 2020.

ZAMPRONHA, E. Notação, representação e composição: um novo paradigma da escritura musical. São Paulo: Annablume: FAPESP, 2000.

Artigo submetido em: 09 mar. 2020

Artigo aceito em: 07 jul. 2020 